\title{
KOMUNIKASI INTERPERSONAL KARYAWAN PADA PELANGGAN DALAM MEMBERIKAN SERVICE EXCELLENT DI PT ZOOM \& WATCH BINTARO
}

\author{
Annie Rufeidah ${ }^{1}$ \\ Dosen Prodi Sekretari D-III Universitas Pamulang \\ dosen01940@unpam.ac.id \\ Katry Anggraini ${ }^{2}$ \\ Dosen Prodi Sekretari D-III Universitas Pamulang \\ icha.driwes@gmail.com \\ Indri Lestari ${ }^{3}$ \\ Mahasiswa Prodi Sekretari D-III Universitas Pamulang \\ lestari.indri121@gmail.com
}

\begin{abstract}
ABSTRAK- Komunikasi Interpersonal terjadi tatap muka secara langsung, pesan tersebut melalui saluran antar personal, terjadinya adanya persaingan ketat pada berbagai bidang menjadikan pekerjaan di dalamnya selalu menginginkan yang terbaik untuk orang lain, terutama mengenai service excellent. Dalam upaya pencapaian keberhasilan suatu perusahaan tidak hanya dipengaruhi besarnya dana, penggunaan teknologi, maupun sarana dan prasarana, yaitu faktor sumber daya manusia. Pendidikan dan pelatihan sangat penting bagi karyawan dalam mengatasi permasalahan komunikasi pada pelanggan seperti pengetahuan, keterampilan, dan sikap, sehingga tidak adanya kesenjangan antara karyawan satu dengan karyawan lainnya begitu pula pada pelanggan untuk menghindari ada terjadinya masalah atau komplain. Penelitian ini memiliki 2 (dua) tujuan adalah untuk mengetahui komunikasi interpersonal karyawan dalam memberikan service excellent di PT Zoom \& Watch Bintaro dan untuk mengetahui cara mengatasi hambatan yang terjadi dalam service excellent kepada pelanggan PT Zoom \& Watch Bintaro. Teknik dalam mengumpulkan data melalui pendataan dilakukan secara langsung dan pengumpulan data dilakukan secara tertulis. Karyawan berkomunikasi dengan pelanggan dapat berbagai cara, tetapi secara umum komunikasi pada dua arah antara perusahaan dengan pelanggan dapat dengan tatap muka langsung atau face to face, melalui telepon, dan lewat surat/email/fax/tertulis. Cara mengatasinya karyawan harus bisa menjelaskan informasi sesuai dengan pertanyaan si pelanggan, melakukan verifikasi dengan permasalahan yang dikeluhkan dan umpan balik yang tepat terhadap pelanggan dan sebaiknya perusahaan melakukan pelatihan khusus mengenai pelatihan bahasa asing dasar secara berkala untuk karyawan, agar mengoptimalkan kinerja karyawan dalam berbicara bahasa asing.
\end{abstract}

Kata-kata Kunci: Komunikasi Interpersonal, Service Excellent, Karyawan, dan Pelanggan.

ABSTRACT-Interpersonal communication takes place in face-to-face contact, where messages flow through interpersonal channels. Very tight competition in various fields of work makes the work involved in it want to provide the best for others, especially with the problem of providing excellent service. The success of a company is certainly not only determined by the amount of funds owned, the technology used, or the facilities and infrastructure, but the most important thing is the human resource factor. Education and training are very important for employees in overcoming communication problems with customers such as knowledge, skills and attitudes, 
so that there is no gap between one employee and another employee as well as the customer to avoid any problems or complaints. This study has 2 (two) objectives to find out employee interpersonal communication in providing excellent service at PT Zoom \& Watch Bintaro and to find out how to overcome obstacles that occur in excellent service to customers of PT Zoom $\&$ Watch Bintaro. The technique in collecting data through data collection is done directly and data collection is done in writing. Employees communicate with customers in many ways, but in general two-way communication between the company and its customers can be classified as: direct contact or face to face, by telephone, and by letter / email / fax / written. How to overcome them employees must be able to explain information in accordance with the customer's questions, verify with the complaints and complaints appropriate to the customer and the company should conduct special training on basic foreign language training on a regular basis for employees, in order to optimize employee performance in speaking a foreign language.

Keywords: Interpersonal Communication, Excellent Service, Employees, and Customers.

\section{PENDAHULUAN}

\section{Latar Belakang}

Komunikasi interpersonal yang dilakukan oleh organisasi atau karyawan perusahaan diperlukan SDM yang memiliki skill/kompetensi dalam berkomunikasi khususnya komunikasi interpersonal. Komunikasi interpersonal dapat membuat lancarnya suatu interaksi karena informasi tersebut yang disampaikan kepada seseorang dapat direspon dengan baik dan efektif bagi penerima pesan. Melakukan komunikasi dapat secara langsung tatap muka, pesan tersalurkan dengan antar personal, seperti dialog yang dilakukan dengan satu atau dua orang secara intens dikenal komunikasi interpersonal.

Adanya berbagai bidang pekerjaan dalam bersaing menjadikan di internal perusahaan ingin memberikan yang terbaik untuk pelanggan atau konsumen, utamanya dengan masalah memberikan service excellent. Karyawan harus bisa menciptakan interaksi yang baik kepada pelangan yaitu melalui komunikasi, karena dengan komunikasi yang sesuai dengan arahan yang diberikan oleh perusahaan maka mampu meningkatkan citra perusahaan yang positif.

Salah satunya PT Zoom \& Watch Bintaro, karyawan dalam memberikan service excellent, khususnya komunikasi yang diberikan kepada pelanggan tidaklah mudah karena selalu saja ada kendala yang dihadapi oleh karyawan misalnya, karyawan tidak fokus dengan apa yang disampaikan oleh pelanggan atau konsumen sehingga terjadi respon yang tertunda di mana respon tersebut akan lama dan pelanggan atau konsumen akan merasa tidak senang, karyawan dalam menyampaikan informasi terkait produk yang disampaikan setengahsetengah atau ragu untuk menyampaikannya sehingga pelanggan atau konsumen tidak jadi 
untuk melanjutkan transaksi dan langsung meninggalkan lokasi.

Sumber daya manusia ataupun karyawan adalah asset bagi perusahaan yang memiliki nilai tinggi, sumber daya manusia atau karyawan yang dimiliki oleh perusahaan dapat dilatih dan dikembangkan, walaupun pada dasarnya sumber daya manusia atau karyawannya sudah mempunyai pengetahuan dan keterampilan yang dibutuhkan, melalui pendidikan dan pelatihan atau training tentunya penting bagi karyawan untuk mengatasi permasalahan yang terjadi khususnya komunikasi pada pelanggan atau konsumen.

Upaya tersebut dilakukan oleh karyawan untuk dapat memberikan service excellent yang baik khsususnya komunikasi pada pelanggan sesuai yang diharapkan karyawan itu sendiri maupun perusahaan. Oleh karena itu dari latar belakang di atas mengacu pada SOP yang berlaku di perusahaan tersebut sehingga karyawan langsung menerapkan service excellent dan komunikasi interpersonal. Pentingnya komunikasi interpersonal antara karyawan dalam memberikan service excellent pada pelanggan. Maka penulis tertarik mengambil judul "Komunikasi Interpersonal Karyawan pada Pelanggan dalam Memberikan Service Excellent di PT Zoom \& Watch Bintaro.”
Adapun perumusan masalah dalam penelitian ini yaitu: (1) Bagaimana komunikasi interpersonal karyawan dalam memberikan service excellent di PT Zoom \& Watch Bintaro? (2) Bagaimana cara mengatasi hambatan yang terjadi dalam service excellent kepada pelanggan melalui komunikasi interpersonal di PT Zoom \& Watch Bintaro? Dan tujuan dari penelitian ini terbagi menjadi 2 (dua), adalah: (1) Untuk mengetahui komunikasi interpersonal karyawan dalam memberikan service excellent di PT Zoom \& Watch Bintaro. (2) Untuk mengetahui cara mengatasi hambatan yang terjadi dalam service excellent kepada pelanggan melalui komunikasi interpersonal di PT Zoom \& Watch Bintaro.

\section{METODE PENELITIAN}

Penelitian membutuhkan data yang terkait dengan studi peneliti tentang:

\section{Jenis Data}

a. Data Primer

Data penelitian ini diperoleh secara langsung melalui sumber aslinya yaitu wawancara, jejak pendapat individu atau kelompok (orang), dan melalui observasi dari obyek, kejadian, maupun hasil pengujian (benda).

b. Data Sekunder

Data dari penelitian ini dihasilkan dari media perantara yaitu buku, 
catatan, dan bukti yang telah sudah ada, atau secara umum menggunakan dokumen publikasi maupun dokumen tidak dipublikasikan.

\section{Teknik Pengumpulan Data}

a. Data Primer

Data penelitian yang didapat dari lapangan yaitu peneliti melakukan observasi atau mengamati secara langsung kegiatan operasional yang dilakukan di tempat penelitian tersebut yaitu PT Zoom \& Watch Bintaro dan melakukan wawancara dengan narasumber yang telah ditentukan oleh peneliti sebagai subjek dalam penelitian.

b. Data Sekunder

Data yang dikumpulkan mempelajari dan mengumpulkan informasi dengan terjun langsung di lapangan.

\section{LANDASAN TEORI}

\section{Komunikasi}

\section{Pengertian Komunikasi}

Menurut Nurudin dalam buku Ilmu Komunikasi (2016:9), mengemukakan bahwa adanya keterlibatan seseorang atau dua orang dalam melakukan proses suatu komunikasi untuk mencoba dalam menumbuhkan suatu kekeluargaan, kebersamaan, atau commones (dalam pesan) kepada orang lain atau komunikan yang diajak berkomunikasi.

Menurut John Fiske, Pengantar Ilmu Komunikasi (2014:17), mengemukakan komunikasi merupakan sebuah proses yang di dalamnya saling berpartisipasi atau komunikasi saling menciptakan pihak yang membagi, menyampaikan, dan pertukaran informasi satu dengan lainnya untuk mencapai kesepakatan bersama.

Menurut peneliti komunikasi mempunyai pengertian luas maupun beragam. Tiap-tiap definisi mempunyai penekanan arti dan konteks yang berbeda satu sama lainnya.

\section{Tujuan dan Fungsi Komunikasi}

Menurut Suryanto dalam buku Pengantar Ilmu Komunikasi (2015:29) tujuan dan fungsi komunikasi dapat dijelaskan sebagai berikut:

\section{a. Tujuan Komunikasi}

Tujuan dari komunikasi yaitu untuk menciptakan keselarasan, kesamaan makna, atau perilaku yang disampaikan dari narasumber ke audiens atau komunikan. Hubungan ini menghadirkan jiwa yang sehat, karena pada dasarnya manusia membutuhkan hubungan sosial antara satu dengan yang lainnya.

\section{b. Fungsi Komunikasi}


Komunikasi tidak hanya berfokus kepada permasalahan dalam pertukaran suatu berita maupun pesan, melainkan kegiatan individu atau kelompok yang terkait pada pertukaran dalam memuat data, fakta, maupun ide-ide. Fungsi dari komunikasi sebagai berikut:

1) Merupakan alat organisasi yang di mana keseluruhan pada kegiatan organisasi dapat diorganisirkan (dipersatukan) dalam mencapai suatu tujuan tertentu;

2) Suatu alat pengubahan perilaku anggota di dalam suatu organisasi;

3) Alat informasi untuk disampaikan ke seluruh anggota di dalam organisasi.

\section{Komponen Komunikasi}

Menurut Cangara dalam buku Pengantar Ilmu Komunikasi (2015:159), komponen-komponen komunikasi sebagai berikut:

a. Komunikator

Komunikator adalah narasumber atau seseorang di mana pihak yang menyampaikan sebuah pesan untuk disampaikan kepada seseorang atau orang lain.

b. Pesan
Pesan yaitu suatu informasi, berita, hiburan, atau lainnya untuk mengajak, menghibur, membujuk, dan sebagainya dengan tepat dan bahasa yang dapat dimengerti oleh lawan bicara komunikator.

c. Media/Channel (Saluran)

Media adalah alat yang digunakan sebagai sarana untuk memproduksi, mereproduksi, mengolah, menyebarkan, dan menyampaikan informasi.

d. Komunikan (communicant)

Komunikan adalah seseorang yang menjadi sasaran/penerima pesan dalam suatu proses komunikasi.

e. Efek (Hail)

Efek adalah dampak dari proses komunikasi, di mana sikap dan tingkah laku seseorang yang dijadikan sasaran dalam komunikasi, sesuai atau tidak sesuai pesan yang dilakukan.

f. Umpan Balik (FeedBack)

Mengetahui tujuan dari pesan tersampaikan atau tidak, umpan balik itu respon negatif atau respon positif.

\section{Komunikasi Interpersonal}

1. Pengertian Komunikasi Interpersonal

Menurut dari Indriyo Gitosudarmo dan Agus Mulyono (2010:196) pengertian komunikasi interpersonal 
adalah komunikasi yang dilakukan secara tatap muka secara langsung (face to face) di mana merupakan suatu hal yang penting untuk pimpinan atau karyawan. Komunikasi interpersonal merupakan salah satu faktor keberhasilan dalam menentukan suatu organisasi dalam mencapai tujuan.

Menurut Djoko Purwanto (2010:4) komunikasi interpersonal ini tidak melibatkan dua orang atau lebih, dan proses pemindahan pesannya dilakukan dengan cara berkomunikasi yang biasa dilakukan oleh seseorang berupa lisan, tulisan, maupun sinyal-sinyal nonverbal.

Dari berbagai definisi di atas dapat dinyatakan bahwa komunikasi interpersonal adalah komunikasi terjadi secara langsung atau tatap muka baik antara satu orang dengan orang lain maupun dengan kelompok, komunikasi ini sangat efektif karena dapat langsung diketahui respon dari komunikan.

\section{Tujuan Komunikasi Interpersonal}

Menurut Muhammad (2009) Tujuan komunikasi tidak perlu hanya disadari pada saat terjadinya pertemuan dan juga tidak perlu ditanyakan, bahwa tujuan ini dapat disadari atau tidak disadari dan dapat disengaja atau tidak disengaja. Diantara tujuan-tujuan itu ialah sebagai berikut:

a. Dapat menemukan diri sendiri b. Dapat menemukan dunia luar

c. Dapat membentuk dan menjaga hubungan antar manusia yang penuh arti

d. Perubahan pada sikap dan tingkah laku

e. Dapat saling membantu

\section{Service Excellent}

\section{Pengertian Service Excellent}

Menurut Pratomo \& Shaff (2010:107)

Service excellent pada intinya yaitu Rasa peduli terhadap organisasi atau organisasi yang berorientasi pada laba (berorientasi laba) yang berorientasi sosial (nirlaba) kepada pelanggan, sebagaimana ditunjukkan oleh adanya sikap, kekhawatiran, dan tindakan nyata, di mana pelanggan merasa nyaman dengan layanan yang disediakan.

Menurut Rahmayanty

(2013:18) service excellent ialah pelayan dengan stadar kualtas yang tinggi dan selalu mengikuti perkembangan kebutuhan pelangan setiap saat, secara konsisten dan akurat.

Berdasarkan penjelasan di atas, peneliti dapat menyimpulkan bahwa dalam mendefinisikan keunggulan layanan dan kepedulian perusahaan terhadap pelanggan, ketika mereka mencoba memberikan atau meningkatkan layanan untuk memenuhi 
harapan dan kebutuhan dua pelanggan, berdasarkan pada standar dan prosedur. Dari layanan hingga memenangkan kepercayaan pelanggan, sehingga Anda puas atau menyadari bahwa pelanggan memiliki loyalitas yang tinggi.

\section{Tujuan Service Excellent}

Terdapat beberapa tujuan service excellent menurut Rahmayanty (2013:1213), yaitu:

a. Memberikan rasa puas dan kepercayaan pada konsumenya.

b. Adanya service excellent tetap menjaga dan merawat pelanggan merasa diperhatikan dan dipentingkan segala kebutuhannya atau keinginannya.

c. Upaya untuk menjaga pelanggan setia terhadap penggunaan produk atau layanan yang ditawarkan.

\section{Etika Dalam Menghadapi Pelanggan}

Bagian etika dalam menghadapi pelanggan terbagi menjadi 7 (tujuh) yaitu:

a. Berpusat pada perhatian pelanggan.

b. Pelanggan diberikan pelayanan yang efektif dan efisien.

c. Harga diri pelanggan diangkat untuk membentuk rasa peduli. d. Adanya hubungan yang baik dengan pelanggan.

e. Mampu menjelaskan dan menerangkan dengan baik kepada pelanggan.

f. Dapat mengetahui dan menentukan keinginan dari pelanggan.

g. Jasa pelayanan memberikan pelayanan yang dapat diberikan perusahaan.

\section{HASIL DAN PEMBAHASAN}

Hasil dan pembahasan ini berdasarkan hasil observasi lapangan dan wawancara pada narasumber dan disesuaikan pula dengan perumusan masalah dan tujuan dari penelitian, yaitu Komunikasi interpersonal karyawan dalam memberikan service excellent di PT Zoom \& Watch Bintaro di mana karyawan berkomunikasi pada pelanggan dengan banyak cara, namun pada umumnya komunikasi dua arah antara perusahaan dan pelanggannya dapat digolongkan menjadi: kontak langsung atau face to face, lewat telepon, lewat surat/email/fax/tertulis.

1. Komunikasi langsung (face to face)

Keberhasilan komunikasi pada dasarnya ditentukan oleh 3 elemen, $7 \%$ oleh katakata, 38\% oleh suara (ucapan) dan 55\% oleh bahasa tubuh.

a. Kata-kata 
1) Menggunakan kata-kata yang tepat;

2) Hindari penggunaan bahasa yang kurang sopan/istilah yang sulit dipahami bagi pelanggan.

b. Suara

1) Karyawan perlu memperhatikan nada suara dan kecepatan bicara terhadap pelanggan;

2) Karyawan harus bisa menyesuaikan intonasi suara dan artikulasi dalam pengucapan agar pelanggan dapat mendengar dengan jelas;

3) Nada yang ramah saat berbicara dan tersenyum;

4) Karyawan dalam menyambut datangnya pelanggan harus tersenyum dan ramah, saat berbicara pada pelanggan karyawan harus berdiri sesuai dengan manner/aturan yang telah ditetapkan oleh perusahaan.

c. Bahasa Tubuh

1) Saat melayani pelanggan karyawan harus melakukan kontak mata dan menampilkan ekspresi wajah yang hangat dan bersahabat;

2) Karyawan harus bisa mengontrol pergerakan tangan, kaki, kepala saat berbicara pada pelanggan. Karena bahasa tubuh dapat diceritakan dan dicerminkan dari apa yang dirasakan dan dipikirkan dari seseorang;

3) Karyawan harus bisa menciptakan kenyamanan terhadap pelanggan dengan cara saat berbicara dengan pelanggan harus bisa jaga jarak dengan pelanggan kurang lebih 1 meter.

\section{Komunikasi Interpersonal Melalui} Telepon

Beberapa hal yang haus diperhatikan karyawan dalam membangun komunikasi telepon efektif dan efisien, dengan cara:

a. Telepon diangkat dengan cepat dan jangan sampai berdering melebihi 2 kali;

b. Dengarkan pelanggan saat sedang berbicara;

c. Apabila ada pelanggan yang keluhan karyawan harus menunjukkan pengertian dan empati;

d. Saat pelanggan melakukan keluhan, karyawan harus dapat mengetahui sebab dan akibat permasalahan yang dikeluhkan serta memberikan informasi yang akurat;

e. Karyawan harus segera mengambil tindakan apabila sudah diketahui 
sebab dan akibat dari komplain yang sudah diketahui;

f. Tutuplah telepon dengan sopan.

Cara mengatasi hambatan yang terjadi dalam service excellent kepada pelanggan melalui komunikasi interpersonal di PT Zoom \& Watch Bintaro adalah cara mengatasi hambatan ketidakjelasan informasi. Karyawan harus bisa menjelaskan informasi sesuia dengan pertanyaan si pelanggan, melakukan verifikasi dengan permasalahan yang dikeluhkan dan umpan balik yang tepat terhadap pelanggan dan cara mengatasi hambatan bahasa. Sebaiknya perusahaan melakukan pelatihan khusus mengenai pelatihan bahasa asing dasar secara berkala untuk karyawan, agar mengoptimalkan kinerja karyawan dalam berbicara bahasa asing.

\section{PENUTUP}

\section{Kesimpulan}

Berdasarkan dari pembahasan dan hasil dalam penelitian yang telah dilakukan oleh peneliti maka dapat diambil kesimpulan bahwa Komunikasi interpersonal karyawan dalam memberikan service excellent di PT Zoom \& Watch Cabang Bintaro yaitu komunikasi langsung (face to face), di mana keberhasilan dalam suatu komunikasi pada dasarnya itu fokus pada 3 elemen di mana $7 \%$ oleh kata-kata, $38 \%$ oleh suara (ucapan) dan $55 \%$ oleh gesture tubuh, dan komunikasi melalui telepon harus disesuaikan dengan SOP yang sudah ditentukan.

Cara mengatasi hambatan yang terjadi dalam service excellent kepada pelanggan melalui komunikasi interpersonal Di PT Zoom \& Watch Bintaro yaitu karyawan harus bisa menjelaskan informasi sesuia dengan pertanyaan si pelanggan, melakukan verifikasi dengan permasalahan yang dikeluhkan dan umpan balik yang tepat terhadap pelanggan dan sebaiknya perusahaan melakukan pelatihan khusus mengenai pelatihan bahasa asing dasar secara berkala untuk karyawan, agar mengoptimalkan kinerja karyawan dalam berbicara bahasa asing.

\section{DAFTAR PUSTAKA}

\section{Sumber Buku}

Andri, Feriyanto.2015. Komunikasi Bisnis (Cetakan Ke-1), Kebumen: MEDIATERA.

Aw, Suranto.2018. Komunikasi Organisasi (Cetakan Ke-1), Bandung: PT REMAJA ROSDAKARYA.

Bintoro, dkk.2017. Manajemen Penilaian Kinerja Karyawan (Cetakan Ke-1), Yogyakarta: GAVA MEDIA.

Cangara, Hafied.2017. Pengantar Ilmu Komunikasi (Edisi Ke-17), Jakarta: 
PT

RAJAGRAFINDO

PERSADA.

Djoko, Purwanto.2011. Komunikasi Bisnis

(Cetakan Ke-4), Jakarta:

PT GELORA AKSARA

PRATAMA.

Effendy, Uchjana Onong.2017. Ilmu

Komunikasi Teori dan Praktek

(Cetakan Ke-28), Jakarta: PT

REMAJA ROSDAKARYA.

Fahmi, Irham.2010. Manajemen Kinerja Teori dan Aplikasi (2010), Bandung: IRHAM FAHMI.

Hasibuan, S.P Malayu.2017. Manajemen Sumber Daya Manusia (Cetakan Ke18), Jakarta: PT REMAJA ROSDAKARYA.

Muhtadi, Saeful Asep.2017. Pengantar Ilmu Komunikasi (Cetakan Ke-2), Jakarta: CV PUSTAKA SETIA. 